\title{
Mucin histochemistry of mucous carcinomas of breast and colon and non-neoplastic breast epithelium
}

\author{
D. J. COOPER ${ }^{1}$
}

From the Department of Pathology, United Sheffield Hospitals

SYNOPSIS Although epithelial mucin has been demonstrated in ordinary mammary duct carcinomas, it is formed profusely in the uncommon mucous carcinomas. A histochemical study of mucous carcinomas of the breast and colon showed that both types produce similar mucins, viz, acid and neutral, although the mammary carcinomas produce more neutral mucin and small amounts of sulphated mucins are produced by colonic tumours. Similar studies on sections of normal breast and cystic mammary dysplasia have shown that intracellular neutral mucin was present in the ducts and lobules, and that intracellular acid mucin was present within cells of the terminal ducts and lobules. It was demonstrated enzymatically that the acid mucins produced by the normal and neoplastic tissues is sialic acid. Hence it can be shown that the mucin produced by mucous carcinomas is of epithelial rather than connective tissue type. It is contended that mucous carcinoma of breast arises by metaplasia of duct cells that have already undergone malignant change and not from the lobules of the breast.

Although mucous carcinomas of the breast represent only $2 \%$ of all mammary carcinomas, these were the first of the histological types to be recognized. Otto in 1816 (quoted by Gaabe, 1908) was probably the first to describe it. These tumours have been credited with a more favourable prognosis (Gaabe, 1908; Geschickter, 1938; Silverberg, Kay, Chitale, and Levitt, 1971).

Although it has long been established that mucous carcinomas of the gastrointestinal tract secrete epithelial mucin (Stinson, 1928), there has been controversy as to the type of the mucin secreted by mammary mucous carcinomas, and it is not widely recognized that mucin is secreted by non-neoplastic epithelial tissue. There is also controversy as to the exact site of origin of the mucous carcinomas of the breast.

The purpose of this study is to confirm the epithelial origin of the mucin produced by mucous carcinoma of the breast, using mucous carcinomas of the colon as a comparison, and to demonstrate that epithelial mucin is produced by non-malignant breast epithelia using sections of normal breast and

'Present address. Department of Pathology, Northern General Hospital, Sheffield.

Received for publication 16 January 1974. of cystic mammary dysplasia. Views on the origin of these tumours are stated.

\section{Materials and Methods}

All the material was obtained from the surgical files of the Sheffield Royal Infirmary. The study was performed on 32 cases of mucous carcinoma of the breast: 18 cases of mucoid carcinoma of the colon; sections of normal breast, 12 sections from the periphery of the breast and six from beneath the nipple to show the major duct system; and six cases of breast tissue showing cystic mammary dysplasia. All specimens were fixed in $4 \%$ formaldehyde solution in normal saline, and processed in paraffin wax. Sections, $5 \mu$, were cut in each case.

\section{Histological appearances}

The histological appearances of mucous carcinoma of the breast have been fully described (Geschickter, 1938). The separation into wholly and partially mucous, though of prognostic importance, is of no importance histochemically. In cases showing cystic mammary dysplasia, sections showed areas of adenosis, duct ectasia, epitheliosis, and apocrine metaplasia 
In colonic tumours both mucous and non-mucous areas are present, the mucous areas being especially prominent at the invading margins of the tumour. Carcinoma cells were orientated around lakes of mucin, as distinct from the pattern of mucin secretion within the mammary tumours, where it was secreted around central masses of cells.

\section{Histochemical Studies}

All sections of tumours were stained with haematoxylin and eosin (HE) together with the following stains for mucin (table I): periodic acid Schiff (PAS) (McManus, 1946) with and without diastase; Alcian Blue and PAS (AB/PAS) (Mowry, 1956); aldehyde fuchsin and AB (AF/AB) (Spicer and Myer, 1960); Alcian Yellow and AB (AY/AB) (Ravetto, 1964); phenylhydrazine-PAS (Phe PAS) (Spicer, 1961); Alcian Blue methylated (AB-meth) (Fisher and Lillie, 1954) when the mild methylation procedure was used; Alcian Bluemethylated followed by saponification (AB-meth-sap) (Spicer and Lillie, 1959) when the strong methylation procedure was employed followed by saponification with potassium hydroxide; metachromatic stains (Hodson and Prout, 1968); Azure A was employed at pH 1.5 and sulphated mucins were metachromatically stained at this pH; high iron diamine method (HID) (Lev and Spicer, 1965) in which sections were exposed for $16 \mathrm{hr}$ to the diamine mixture. Sialidase AB/PAS(Spicer and Warren, 1960) for which sialidase enzyme from Vibrio cholerae, 500 units per $\mathrm{ml}$ at $\mathrm{pH} 5 \cdot 5$, was obtained from Koch Light Laboratories. Sections were exposed to the enzyme for $24 \mathrm{hr}$ at $37^{\circ} \mathrm{C}$.

Because amounts of mucin produced in nonneoplastic breast are small, tissue stains which could

\begin{tabular}{llll}
\hline Stain & Mucin Demonstrated & \multicolumn{2}{l}{ Mucous Carcinoma } \\
\cline { 3 - 4 } & & Breast & Colon \\
\hline PAS & Non-specific neutral & + & + \\
PAS-Diastase & Non-specific neutral & + & + \\
AB/PAS & Acid/neutral & Acid + & Acid + \\
& & Neutral + & Neutral + \\
AF/AB & Sulphated & - & \pm \\
AY/AB & Carboxylated & + & + \\
Phe PAS & Neutral & + & + \\
AB Meth & Sulphated & - & - \\
AB Meth Sap & Carboxylated & + & + \\
Azure A & Sulphated & - & \pm \\
H.I.D. & Sulphated & - & - \\
AB/PAS sialidase & Sialic acid & + & + \\
\hline
\end{tabular}

Table I Histochemical reactions of the mucin in mucous carcinoma of breast compared with that in mucous carcinoma of colon

\footnotetext{
+ All cases

\pm Some cases

- None
}

\begin{tabular}{llllll}
\hline Stain & $\begin{array}{l}\text { Mucin } \\
\text { Demonstrated }\end{array}$ & $\begin{array}{l}\text { Duct } \\
\text { Cells }\end{array}$ & $\begin{array}{l}\text { Duct } \\
\text { Lumen }\end{array}$ & $\begin{array}{l}\text { Lobule } \\
\text { Cells }\end{array}$ & $\begin{array}{l}\text { Lobule } \\
\text { Lumen }\end{array}$ \\
\hline AB/PAS & Acid & - & + & + & + \\
& Neutral & + & + & + & + \\
AB/PAS diast. & Acid & - & + & + & + \\
& Neutral & + & + & + & + \\
AF/AB & Sulphated & - & - & - & - \\
Azure A & Sulphated & - & - & - & - \\
AB/PAS sial. & Sialic acid & - & + & + & + \\
\hline
\end{tabular}

Table II Histochemical reactions of mucin demonstrated in normal breast tissue

best demonstrate this were used (table II), namely, AB/PAS with and without diastase; AB/PAS without sialidase; AF/AB; and Azure A.

\section{Results}

\section{TUMOURS}

Table I shows the findings for the mucous tumours of breast and colon. In both tumours the PAS reaction was positive and not altered by pretreatment with diastase. AB/PAS gave similar results for both types of tumours though more neutral mucin was produced by the mammary tumours. This was confirmed using Phe PAS. None of the colonic tumours showed a predominance of neutral mucin. Many of the colonic tumours contained some sulphated mucin as demonstrated by reactivity to AF/AB Meth AB and metachromasia with Azure A. The HID method showed no marked reaction for any of the tumours, though colonic mucosa close to tumour tissue did react. None of the mammary tumours were shown to contain sulphated mucins. The acid mucin within both groups of tumours was shown to be carboxylated mucin using Meth Sap/AB whereby the $A B$ reactivity was restored, and the AY/AB when the tumours showed a greater affinity for AY. Some of the colonic tumours showed green, indicating mixtures of carboxylated and sulphated mucins. It was demonstrated that those areas of mucin which took up $A B$ and $A Y$ were digested by sialidase with replacement of $A B$ reactivity by PAS.

It was noted in the mucous carcinoma of the breast that within areas of normal breast tissue beside the tumours mucin was present within the ducts having the same staining characteristics as tumour mucin. Although it could be argued that this was the result of mucin diffusing into the ducts from the adjacent tumour, it was noted that individual cells within the terminal ducts and lobules also contained mucin. It was considered necessary, therefore, to investigate non-neoplastic breast tissue for mucin. Table II shows the findings for nonneoplastic breast. Using AB/PAS, mucin was found within the lumina of the duct system and lobules. 
This was neutral mucin as it was not digested by diastase, as was the PAS reactivity of granules within the cytoplasm of the myoepithelial cells. Similar mucin was present within the cytoplasm of the duct epithelial cells. Acid mucin was shown to be present within the lumen of the ducts and within the cytoplasm of the lobular epithelial cells by the uptake of AB. No sulphated mucin was demonstrated by $\mathrm{AF} / \mathrm{AB}$ nor Azure A metachromasia at $\mathrm{pH} \mathrm{1.5}$. As with the carcinomas the acid mucin was shown to be sialidase-labile sialomucin. The findings for cystic mammary dysplasia were similar for those of normal breast though much more mucin was present within the lumina. Within the cytoplasm of duct cells that had undergone so-called apocrine metaplasia PAS-positive, diastase-resistant globules were present, which were more prominent than those seen in ordinary ducts. In neither the normal breast nor that showing cystic mammary dysplasia was there any evidence of intracytoplasmic secretion of mucin within the major ducts beneath the nipple. The amount of mucin produced by non-neoplastic breast epithelia was not related to the age of the patient.

\section{Discussion}

Mucins are complex carbohydrates secreted by epithelial and connective tissue cells. They are composed of hexosamine units combined with glucuronic or sialic acid. Some mucins contain sulphate esters in addition.

Numerous types of mucin occur depending on the site of production. Examples of connective tissue mucins are chondroitin sulphate, heparin sulphate, keratan sulphate, and hyaluronic acid. Epithelial mucins may be acid or neutral. Neutral mucins are hexosamine units without free acidic groups. Acid mucins consist of hexosamine units which may be associated with glucuronic or sialic acid, the reactive group being a carboxyl. In sulphated mucins this group is blocked by a sulphate group which becomes the active group. Strongly sulphated mucins are of connective tissue type; the weakly sulphated groups are of epithelial type. The non-sulphated mucins are sialic acid and hyaluronic acid (carboxylated D-glucuronic acid). These can be enzymatically digested, though enzyme-resistant forms do occur.

The presence of carboxyl groups or sulphate groups was determined by the various staining techniques described and confirmed using enzyme digestion methods.

Until relatively recently the type of mucin in mucous carcinoma of the breast has remained in doubt. It is of interest that Lange (1896), who stained his sections with toluidine blue, concluded that the mucin was of connective tissue origin. However, Gaabe (1908) using the same stain concluded that the mucin was of epithelial origin, a theory first propounded by Virchow (quoted by Lee, Hauser, and Pack, 1934). Ewing (1922) favoured a dual origin from both connective tissue and epithelium but also in some cases from fat. The first histochemical study performed in order to ascertain the type of mucin was by Grishman (1952) who demonstrated its epithelial origin. Since then many histochemical studies of mucous carcinoma of the breast have appeared in the North American literature. Norris and Taylor (1965) found the mucin to be a poorly sulphated mucopolysaccharide, though Spicer, Neubeeker, Warren, and Henson (1962) had shown this to be enzymatically digestible sialic acid. The present study has confirmed the presence of sialomucin but abundant neutral mucin has also been demonstrated. Occasionally a mammary carcinoma may show marked mucin production within the stroma. However, apart from the different histochemistry of stromal mucin, the histological appearances are distinct from that of a mucous carcinoma.

It has been firmly established that mucous carcinomas of the gastrointestinal tract secrete mucin of epithelial type, and Stinson as early as 1928 asserted that mucous carcinomas of the stomach produce epithelial mucins on histological grounds. More recently sialic acid has been demonstrated in carcinoma of the colon (Filipe, 1969; Subbuswamy, 1971). From these studies it could be inferred that mucous carcinomas of the colon produce sialic acid. Roberts and Burns (1972) demonstrated sialic acid in pancreatic adenocarcinomas, and Gad (1969) sulphated mucin and sialic acid in adenocarcinomas of the gastrointestinal tract arguing that sulphomucin predominated in the well differentiated adenocarcinomas.

The site of origin of these tumours within the breast has remained doubtful. Since mucin was demonstrated within lobular epithelial cells, it would be tempting to suggest that these tumours arose within the lobules. However, most areas of nonmucous carcinoma seen within the partially mucous carcinomas showed the scirrhous pattern characteristic of duct carcinoma. A few tumours, however, showed the pattern of an infiltrating lobular carcinoma with the 'Indian file' arrangement of cells around normal ducts at the invading part of the tumour. These tumours were reviewed recently by Ashikari, Huvos, Urban, and Robbins (1973), who showed that these forms of mammary carcinoma have a worse prognosis and a notorious tendency to occur in the opposite breast.

Willis (1967) thought that the mucin in mucous carcinomas arose through metaplasia within an 
ordinary duct carcinoma. The finding of intraduct and invasive carcinoma next to mucous areas would be accounted for by this mode of formation. It appears that the stage in evolution of a tumour at which it becomes mucous would explain the variable amounts of mucin produced. A tumour that underwent mucous metaplasia late in the course of its evolution would have the least mucin. Many tumours in the series showed intraduct carcinoma in which globules of mucin were present. This was both acid and neutral, whereas only neutral mucin has been identified in cells lining the ducts, so that when malignant change occurs sialic acid is also produced. Since sialic acid is a nine-carbon compound, it is more complex than neutral mucin, which is a six-carbon compound. Furthermore sialic acid occurs in most mammalian mucous membranes, so it cannot be argued that a more primitive mucin is produced when malignant change occurs.

Thanks are due to $\mathrm{Mr} \mathrm{P}$. Lonsdale for technical assistance, to Mrs A. M. Robinson for secretarial assistance, and to Dr L. Henry for helpful criticism. The work was supported by the Yorkshire Council of the Cancer Research Campaign.

\section{References}

Ashikari, R., Huvos, A. G., Urban, J. A., and Robbins, G. F. (1973). Infiltrating lobular carcinoma of breast. Cancer (Philad.), 31, 1, 110-116.

Ewing, J. (1922). Neoplastic Diseases, 2nd ed., p. 513. Saunders, Philadelphia.

Filipe, M. I. (1969). Value of histochemical reactions for mucosubstances in the diagnosis of certain pathological conditions of the colon and rectum. Gut, 10, 577-586.

Fisher, E. R., and Lillie, R. D. (1954). The effect of methylation on basophilia. J. Histochem. Cytochem., 2, 81-87.

Gaabe, G. (1908). Der Gallertkrebs der Brustdrüse. Beitn. klin. Chir., $60,760-807$.

Gad, A. (1969). A histochemical study of human alimentary tract mucosubstances in health and disease. I. Normal and tumours. ii. Inflammatory conditions. Brit. J. Cancer, 23, 52-68.

Geschickter, C. F. (1938). Gelatinous mammary cancer. Ann. Surg., 108, 321-346.

Grishman, E. (1952). Histochemical analysis of mucopolysaccharides occurring in mucus-producing tumors. Cancer (Philad.), 5, 700-707.

Hodson, J. J., and Prout, R. E. S. (1968). Chemical and histochemical characterization of mucopolysaccharides in a jaw myxoma. J. clin. Path., 21, 582-589.

Lange, F. (1896). Der Gallertkrebs der Brustdrüse. Beitn. klin. Chir., 16, 1-60.

Lee, B. J., Hauser, H., and Pack, G. T. (1934). Gelatinous carcinoma of the breast. Surg. Gynec. Obstet., 59, 841-857.

Lev, R., and Spicer, S. S. (1965). A histochemical comparison of human epithelial mucins in normal and hypersecretory states including pancreatic cystic fibrosis. Amer. J. Path., 46, 23-47.

McManus, J. F. A. (1946). Histological demonstration of mucin after periodic acid. Nature (Lond.), 158, p. 202.

Mowry, R. .W. (1956). Alcian blue technics for the histochemical study of acidic carbohydrates. J. Histochem. Cytochem., 4, 407.

Norris, H. J., and Taylor, H. B. (1965). Prognosis of mucinous (gelatinous) carcinoma of the breast. Cancer (Philad.), 18, 2, 879888.

Ravetto, C. (1964). Alcian blue-alcian yellow: a new method for the identification of different acidic groups. J. Histochem. Cytochem., 12, 44-55.

Roberts, P.S., and Burns, J. (1972). A histochemical study of mucins in normal and neoplastic human pancreatic tissue. J. Path., 107, 87-94.

Silverberg, S. C., Kay, S., Chitale, A. R., and Levitt, S. H. (1971). Colloid carcinoma of the breast. Amer. J. clin. Path., 55, 355-363.

Spicer, S. S. (1961). The use of various cationic reagents in histochemical differentiation of mucopolysaccharides. Amer. J. clin. Path., 36, 393-407.

Spicer, S. S, and Lillie, R. D. (1959). Saponification as a means of selectively reversing the methylation blockade of tissue basophilia. J. Histochem. Cytochem., 7, 123-125.

Spicer, S. S., and Meyer, D. B. (1960). Histochemical differentiation of acid mucopolysaccharides by means of combined aldehyde fuchsin-alcian blue staining. Amer. J. clin. Path., 33, 453460.

Spicer, S. S., Neubecker, R. D., Warren, L., and Henson, J. G. (1962). Epithelial mucins in lesions of the human breast. J. nat. Cancer Inst., 29, 963-970.

Spicer, S. S., and Warren, L. (1960). The histochemistry of sialic acid containing mucoproteins. J. Histochem. Cytochem., 8, 135-137.

Stinson, J. W. (1928). Colloid carcinoma of the stomach. Surg Gynec. Obstet., 46, 180-186.

Subbuswamy, S. G. (1971). Mucosubstances in neoplasms of the colon and rectum. Gut, 12, 200-207.

Willis, R. A. (1967). Pathology of Tumours, 4th ed., p. 238. Butterworths, London. 